\title{
Ab initio Calculations of Partial Charges at Kaolinite Edge Sites and Molecular Dynamics Simulations of Cation Adsorption in Saline Solutions at and Above the $\mathrm{pH}$ of Zero Charge
}

\section{Supporting Information}

Gonzalo R. Quezada, ${ }^{a}$ Roberto E. Rozas,${ }^{b}$ Pedro G. Toledo ${ }^{c^{*}}$

${ }^{a}$ Water Research Center for Agriculture and Mining (CRHIAM), Universidad de Concepción, Victoria 1295, Concepción, Chile

${ }^{b}$ Department of Physics, Universidad del Bío-Bío, PO Box 5-C, Concepción, Chile

${ }^{c}$ Department of Chemical Engineering and Laboratory of Surface Analysis (ASIF), Universidad de Concepción, PO Box 160-C, Correo 3, Concepción, Chile

Corresponding author

*E-mail: petoledo@udec.cl (P.G.T.) Phone 56-41 2203658

\section{ORCID}

Pedro G. Toledo: 0000-0003-2863-7997

Gonzalo R. Quezada: 0000-0002-8670-6260

Roberto E. Rozas: 0000-0002-6466-5162
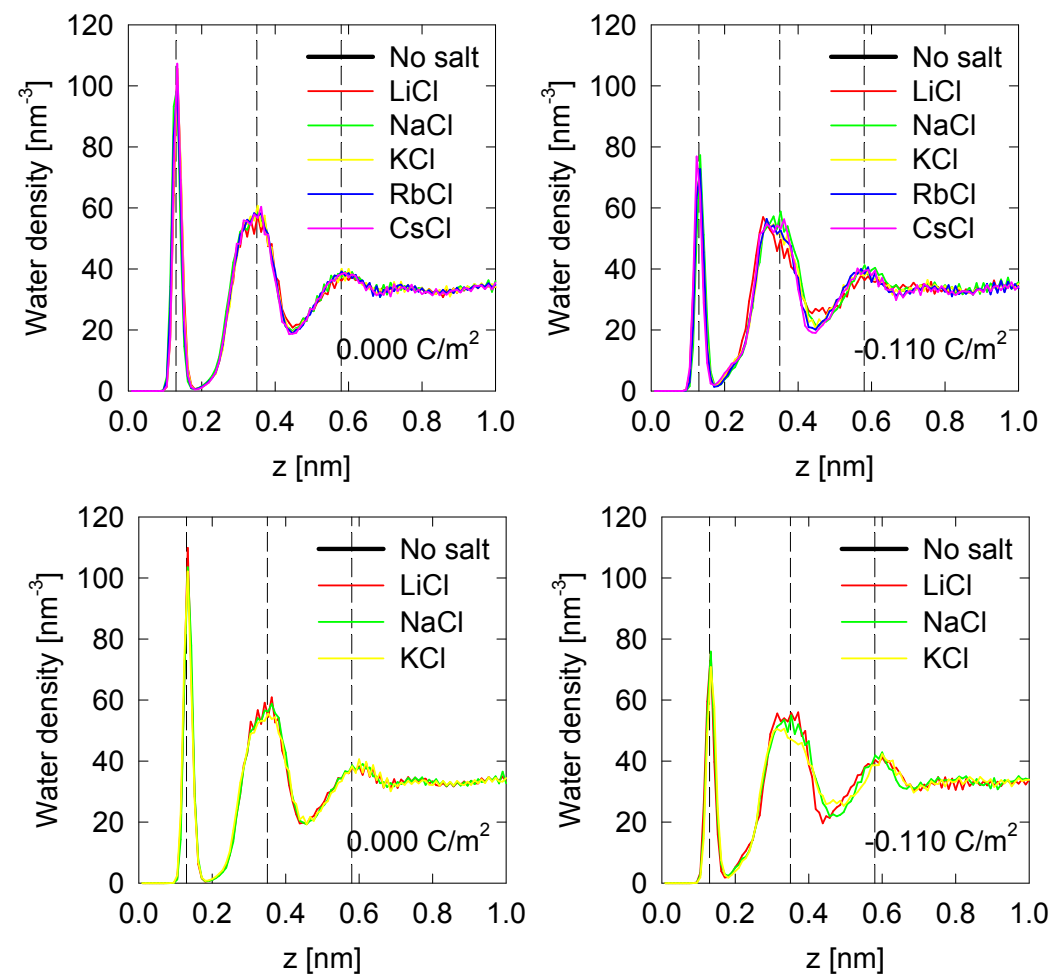

Figure S1 Axial density profiles of water in the presence of solutions of alkali and alkaline-earth metals close to neutral and negatively charged (010) edge surfaces of kaolinite at $300 \mathrm{~K}$. Mean position of peaks are represented by segmented vertical lines. 